\title{
Método de Teclado e Violão à Distância com a utilização das novas TICs
}

\author{
Fátima Weber Rosas -UFRGS - fatima@ caef.ufrgs.br* \\ Bruno Westermann - UFBA - brwestermann@gmail.com**
}

\section{Resumo:}

Este artigo apresenta um relato sobre o ensino de Teclado e Violão em modalidade EAD, no Curso de Licenciatura em Música a Distância da Universidade Federal do Rio Grande do Sul (PROLICENMUS). A fundamentação dos dois métodos, a estrutura de seus objetos virtuais de arpendizagem e da interdisciplina Seminário Integrador, na qual são utilizados, também são relatadas no presente trabalho. Concluise falando sobre sua viabilidade, à luz de um breve panorama de pesquisas realizadas na área e propostas de ensino superior de música através da modalidade EAD no Brasil e em outros países.

Palavras chave: Ensino de instrumento musical à distância; objeto virtual de aprendizagem; educação à distância.

\section{Keyboard and Guitar's Methodology in Distance Learning by using new TICs}

\begin{abstract}
This paper presents the account about Keyboard and Guitar teaching in Distance Learning Music Education Course at Universidade Federal do Rio Grande do Sul. The methodology's base, the structure of learning objects and the subject Integrator Seminary are accounted too on this paper, with the general investigations in this area and proposals about Distance Learning Music Education graduate and postgraduate degree programs on Brazil and other countries.
\end{abstract}

Keywords: Musical instrument teaching in Distance Learning; learning object; distance learning.

\footnotetext{
* Integrante do grupo de pesquisa Proposta Musicopedagógica CDG (PROPESQ da UFRGS e Diretório de Grupos de Pesquisa do CNPq). Tutora na Universidade no Curso de Licenciatura em Música, modalidade EAD; Especialista em Artes e Educação Física na Educação Básica; Integrante da equipe de pesquisa e desenvolvimento do ebook teclado (CAEF/UFRGS).

* * Mestrando em Música na Universidade Federal da Bahia, Integrante da equipe de pesquisa e desenvolvimento do ebook violão (CAEF/UFRGS) e Tutor no Curso de Licenciatura em Música a distancia da UFRGS.
} 


\section{INTRODUÇÃO}

Baseadas nos avanços tecnológicos ocorridos nas últimas décadas, surgiram novas formas de comunicação e transmissão cultural, sendo a Internet a principal delas. Com o passar do tempo, as tecnologias digitais foram sendo cada vez mais aplicados ao uso educacional e a educação a distância passou a ser mediada por elas, usufruindo dos recursos oferecidos pela World Wide Web. Atualmente, são milhares de pessoas interconectadas, utilizando-se do computador e da Internet como ferramentas de comunicação e interação, formando comunidades virtuais, propiciando o desenvolvimento de um processo educacional, visando a produção de conhecimento individual e grupal em processos colaborativos favorecidos pelo uso de ambientes digitais e interativos de aprendizagem, os quais permitem romper com as distâncias espaço-temporais entre alunos e professores.

O advento das tecnologias de informação e comunicação (TIC) reavivou as práticas de $\mathrm{EaD}$ devido à flexibilidade do tempo, quebra de barreiras espaciais, emissão e recebimento instantâneo de materiais, o que permite realizar tanto as tradicionais formas mecanicistas de transmitir conteúdos, agora digitalizados e hipermediáticos, como explorar o potencial de interatividade das TIC e desenvolver atividades à distancia com base na interação e na produção de conhecimento. (Almeida, 2003, p.330).

Embora no Brasil a educação a distância tenha ficado por muito tempo restrita a iniciativas de educação supletiva ou de formação profissional de nível básico, a partir de 1990 este cenário começa a se modificar. A lei de Diretrizes e Bases, aprovada em 1996, dedica o artigo 80 à educação a distância e no mesmo ano é instituída a Secretaria de Educação a Distância na estrutura interna do Ministério da Educação. A partir daí, esta modalidade de educação começa a crescer no país. Como resultado desse crescimento ocorrido ao longo dos últimos anos, em 2007 iniciou-se o Curso de Licenciatura em Música a distância, o PROLICEMUS, do Programa Pró-Licenciaturas do MEC, sob a responsabilidade do Instituto de Artes da Universidade Federal do Rio Grande do Sul (UFRGS), visando a formação dos professores de música da rede pública de ensino que atuam na área de Música, mas ainda não possuem a habilitação legal exigida.

O curso PROLICENMUS também conta com diversas universidades parceiras, que trabalham na pesquisa e no desenvolvimento de materiais para ensino de música EAD. Essas universidades parceiras também auxiliam no gerenciamento dos pólos deste curso, espalhados por cinco estados do Brasil. São elas a Universidade do Estado de Santa Catarina (UDESC), Universidade Federal de Alagoas (UFAL), Universidade Federal da Bahia (UFBA), Universidade Federal do Espírito Santo (UFES), Universidade Federal do Mato Grosso (UFMT), Fundação Federal de Rondônia (UNIR). Todas atuam no Pró-Licenciatura fase II, que foi instituído pela Resolução FNDE $n^{\circ}$ 34/2005 e teve início no ano de 2006. Sob a coordenação da Profa. Dra. Helena de Souza Nunes, professores pesquisadores das sete Universidades Parceiras juntamente com a equipe de produção do CAEF da UFRGS criam objetos de aprendizagem e materiais educacionais digitais de maneira colaborativa. Dentre eles, destacamos aqui, os E-books Teclado e Violão.

\section{ENSINO SUPERIOR DE MÚSICA EAD E UTILIZAÇÃO DAS NOVAS TICs}


O ensino de música na modalidade a distância vem crescendo consideravelmente, tanto no Brasil quanto no resto do mundo. No nosso país, até final de 2008, três eram os cursos em andamento que oferecem graduação em música nesta modalidade de ensino: Universidade de Brasília e o da Universidade Federal de São Carlos (ambos vinculados a Universidade Aberta do Brasil) e o Curso de Licenciatura em Música da UFRGS, vinculado ao ProLicen. Este último, por ter iniciado antes dos outros dois cursos, pode ser considerado um marco para a educação musical brasileira, pois é o primeiro curso de licenciatura em música na modalidade a distância a ocorrer no nosso país.

Fora do Brasil, sabe-se que Universidades como a Boston University Online oferecem cursos Superiores a distância de Mestrado (Master of Music in Music Education - MusM) e Doutorado (Doctor of Musical Arts in Music Education MusAD) em Educação Musical. A Universidade Autônoma de Barcelona também oferece cursos de Pós-Graduação (Especialização e Mestrado) em Educação Musical. Nesses, não se verifica a presença de alguma disciplina prática voltada ao ensino ou aperfeiçoamento da performance instrumental, mas apenas disciplinas focadas na teoria musical, na musicologia e na didática da música.

A Auburn University realizou um programa de desenvolvimento e avaliação do curso de Mestrado em Educação Musical a distância, realizado em três etapas, durante três verões consecutivos. A descrição de como foi criado, quais os aspectos positivos e negativos, dificuldades e facilidades, ferramentas e tecnologia utilizada, assim como os resultados obtidos por este programa se encontram no artigo Program Development And Evaluation Of A Distance Learning Graduate Degree Program In Music Education: Perspectives From Students And Professors, escrito pela professora Dra. Kimberly Walls (2005) e equipe. De acordo com o artigo, estes cursos ocorrem de forma semipresencial, acontecendo no campus com transmissão através de videoconferência e apresentações em Power Point (portanto, buscando atender os alunos presentes e distantes do campus), de forma síncrona. Segundo Walls (et tal, 2005, p.04), foram utilizados dois ambientes gerenciadores do sistema durante o curso: o WebCT ${ }^{1}$ e o Live Classroom $^{2}$. Dentre as possibiliades do Live Classroom estão a comunicação através de voz sobre IP (VoIP) multidirecional; recurso streaming de vídeo unidirecional; chats públicos e privados; área de conteúdo flexível, com possibilidade de mostrar arquivos Power Point, Word, Excel, páginas web, imagens, vídeos, PDFs; testes e questionários em tempo real; partilha de aplicações, permitindo ao docente mostrar a janela da aplicação onde está trabalhando; base em Flash. Nestes ambientes também se encontram ferramentas como módulos, discussões, correio, calendário, testes, tarefas, apresentações e homepage dos alunos e a opção minhas categorias. De acordo com Walls (et tal, 2005), o curso obteve muito sucesso. Diversas ferramentas de interação foram utilizadas, e de acordo com a avaliação, os alunos distantes ajudaram a trazer uma diversidade de pensamento, enriquecendo as discussões e a experiência da comunidade virtual.

\footnotetext{
${ }^{1}$ WebCT (web-based course tools) ou Blackboard Learning System são Sistemas de Ensino a Distância que gerenciam ambientes de ensino a distância a partir de conteúdos inseridos por instrutores e/ou professores. (Dicionário on-line Wikipédia).

${ }^{2}$ Horizon Wimba Live Classroom é uma ferramenta que permite ao docente criar aulas virtuais junto a uma plataforma de ensino, alargando as funcionalidades disponíveis nesta, facilitando o processo de comunicação, trabalho cooperativo , acompanhamento tutorial, combinando as tecnologias de voz, vídeo, partilha de aplicações, quadro branco, etc com as técnicas tradicionais de ensino. Disponível em: http://www.ipg.pt/e-learning/pdf/Horizon_Wimba_Live_Classroom_e_Voice_Tools_INTROv1.pdf. Acesso em 19 de jan de 2009.
} 


\section{ENSINO DE INSTRUMENTO A DISTÂNCIA}

No Brasil, atualmente, além dos trabalhos realizados pela equipe do CAEF da UFRGS, há outros autores que abordam o ensino de instrumento através da EAD, utilizando as novas TICs. Podem ser citados os trabalhos de Braga (2006), Braga e Tourinho (2006) e Gohn (2003) sobre o ensino de instrumento através da EAD. Além destes, Henderson Filho (2007) e Souza (2004) também desenvolvem iniciativas na área de formação continuada de professores através da EAD. Outras, de desenvolvimento e aplicação de propostas de ensino instrumental EAD, vêm sendo realizadas principalmente por escolas particulares de música. No PROLICENMUS, a plataforma de aprendizagem utilizada é o Moodle, onde são encontradas as interdisciplinas do curso, com orientação semanal passo-a-passo. Na interdisciplina chamada Seminário Integrador, encontram-se quinze Unidades de Estudo por semestre, que remetem aos $E$ books Teclado Acompanhamento e Violão Acompanhamento. Cada um dos E-books possui site próprio, contendo o material digital educacional do curso.

\subsection{FUDAMENTAÇÃO DOS E-BOOKS}

A palavra e-book é uma abreviação do termo Eletronic Book (Livro Eletrônico), formato no qual estão sendo desenvolvidos os métodos Violão Acompanhamento e Teclado Acompanhamento. Esse formato vem sendo adotado para que possa ser acessado por equipamentos eletrônicos como computadores, PDAs e alguns celulares, via internet, CD-ROM's ou pen drives. Os e-books de que trata este artigo estão fundamentados no $\mathrm{MAaV}^{3}$ (Musicalização de Adultos Através da Voz), método que visa a musicalização a partir da prática do canto. $\mathrm{O}$ método MAaV foi concebido originalmente na dissertação de mestrado intitulada Musicalização de Adultos Através da Voz - Uma Proposta Metodológica de Abordagem Multi-modal, de autoria de Helena de Souza Nunes Wöhl-Coelho, concluída em 1990, junto ao Curso de Mestrado em Música da UFRGS. A autora passou a dedicar-se à alfabetização musical de adultos, adotando a Abordagem Multimodal a partir e de seu contato com a proposta Explorando Música através do Teclado, de Marion Verhaalen, sistematizadora da Abordagem Multimodal. De acordo com Nunes (2005, p.16), numa abordagem multimodal todos são capazes de aprender, principalmente se os professores e os próprios alunos descobrem seus estilos individuais de aprendizagem. Nesta abordagem o rendimento do aluno também está relacionado com sua auto-estima e com seu auto-conceito, partindo-se do princípio de que todos são capazes de aprender música. Ao longo das Unidades de Estudo os alunos vão se tornando mais musicais, perpassando a alfabetização musical até chegar a uma musicalização ${ }^{4}$ propriamente dita.

\footnotetext{
${ }^{3} \mathrm{O}$ MAaV (Musicalização de Adultos Através da Voz) é um método de ensino de canto para adultos criado pela Dra. Helena de Souza Nunes, utilizado no curso de extensão OTP (Oficinas de Teoria e Percepção) da UFRGS, posteriormente adaptado para professores no âmbito do CAEF da UFRGS que propõe vivências musicais baseadas na prática de cantar.

4 "Com base nos conhecimentos adquiridos ao longo das unidades deste método, provavelmente seja possível promover uma boa dose de autonomia musical nos professores, tornando-os capazes de ler partituras não tão simples, de descobrir e da adaptar cançôes para os seus alunos, e de estimulá-los a reconhecer a própria capacidade de continuar aprendendo música. Esse conjunto de habilidades e interesses é denominado, para efeitos deste método, musicalização". (NUNES, 2005, p.19).

“[...] Assim sendo, musicalizar significa "tornar musical”. (NUNES, 2005, p.18).

V. 7 N $^{\circ}$ 2, Outubro, 2009
} 
Essa abordagem propõe uma musicalização que integra sentidos, memória, compreensão, emoção e criatividade, simultaneamente, todos elaborados dentro da prática de repertório e da técnica. Os conceitos são adquiridos de forma dinâmica e utilizando diversos procedimentos e modos de ensino-aprendizagem, que partem sempre da experiência [...]. (Nunes, 2005, p.16).

Resgatando a proposta inicial da professora Dra. Helena de Souza Nunes, o curso de extensão denominado Oficinas de Teoria e Percepção Musical (OTP) do Departamento de Música da UFRGS em 2003, atualizou e aplicou o MAaV, integrando-o à Proposta Musicopedagógica $C D G^{5}$, apresentando resultados positivos após sua testagem. No mesmo ano, o Ministério de Educação e Cultura lançou o Edital SEIF-MEC no 01/2003, visando selecionar vinte centros para a formação continuada de professores, sendo que destes vinte, três eram destinados às Áreas de Artes e Educação Física. A partir deste edital, foi criado o CAEF da UFRGS (Centro de Artes e Educação Física). Em 2005, o MAaV foi aprovado para o Programa de Formação Inicial para Professores do Ensino Fundamental e Médio (Pró-Licenciatura), gerando novos direcionamentos e ampliações até tornar-se um Objeto de Aprendizagem, utilizado no Programa Pró-Licenciatura II.

Os conteúdos musicais do $\mathrm{MAaV}$, assim como os dos E-books Teclado Acompanhamento e Violão são distribuídos ao longo de quinze unidades, por nível de complexidade progressivo. No $\mathrm{MAaV}$, cada Unidade traz apenas alguns pontos sobre todos os parâmetros musicais, não se esgotando todas as informações sobre o conteúdo de cada parâmetro, mas deflagrando a idéia de uma espiral, na qual um mesmo conteúdo vai sendo abordado e aprofundado de diversas maneiras. A construção de um conjunto de conhecimentos de fato consistentes se dará ao final das quinze unidades. A sua estrutura se baseia também no Quadro Sinóptico de conteúdos, que consiste numa distribuição dos conteúdos ao longo das quinze unidades, buscando sistematizar a sucessão dos tópicos e clarificar a construção do conjunto de informações sobre cada parâmetro musical. Cada unidade aborda pontos sobre os parâmetros Melodia, Ritmo, Harmonia, Forma, Textura, Expressão e Timbre. Além dos E-books possuírem seus conteúdos distribuídos ao logo de quinze unidades por ordem progressiva de dificuldade, sua estrutura também está baseada no Quadro Sinóptico. De forma semelhante ao MAaV, que tem como ponto de partida para o processo de musicalização uma canção principal em cada Unidade, os conteúdos e habilidades abordadas nos E-books também partem de uma peça para cada Unidade, contendo uma espécie de resumo dos conteúdos e habilidades técnicas previstas para aquele determinado estágio do desenvolvimento, denominada Peça da Unidade.

Sendo assim, fundamentados na estrutura e na metodologia do MAaV, os $E$ books Teclado Acompanhamento e Violão Acompanhamento propõem o estudo do teclado e do violão com função de acompanhadores do canto. São métodos de ensino de teclado e violão a distância, que se apresentam sob a forma de objetos virtuais de aprendizagem, visando o despertar da musicalidade integral da pessoa. Tal musicalidade se desenvolve concomitantemente ao aprimoramento do seu domínio instrumental, acreditando que a musicalidade seja inerente a todas as pessoas e que se for estimulada, cresce e se manifesta formalmente.

\subsection{E-BOOKS TECLADO E VIOLÃO ACOMPANHAMENTO}

\footnotetext{
${ }^{5}$ Tese de Doutorado (Cante e Dance com a Gente: ein Projekt für die Musikerziehung in Brasilien, defendida pela prof ${ }^{a}$ Helena de Souza Nunes, na Universidade de Dortmund, Alemanha, em 1998 e publicada em 1999).

V. $7 \mathrm{~N}^{\circ}$ 2, Outubro, 2009
} 
Por terem sido desenvolvidos conjuntamente, tanto E-books de Teclado quanto o de Violão mantém muitos pontos comuns em relação a sua estrutura e na abordagem dos materiais. A principal característica de ambos é o fato de estarem mais focados na formação do músico capaz de cantar e de se acompanhar ao instrumento com destreza, do que na do performer em sentido mais convencional. Não se tem como objetivo formar um instrumentista virtuoso, com amplo domínio técnico nem dedicado ao repertório tradicional erudito. A busca principal está no desenvolvimento de habilidades que sejam úteis para os professores de música do ensino regular da Escola Básica. Diante de um olhar tão diferenciado, tanto o E-book Teclado (http://caef.ufrgs.br/produtos/ebook2008_mec/) quanto o E-book Violão (http://caef.ufrgs.br/produtos/ebook_violao), desenvolvidos por uma equipe interdisciplinar do CAEF da UFRGS, estão em constante aprimoramento.

Cada unidade dos E-books possui uma Peça de Unidade (peça instrumental ou canção que busca resumir todas as dificuldades técnicas trabalhadas naquela unidade). Cada uma dessas peças dispõe de gravação de áudio e vídeo, partitura e uma análise detalhada sobre diferentes aspectos musicais. Seções com ênfases em leitura de partitura e acompanhamento também são comuns aos dois E-books. O repertório trabalhado dá prioridade ao acompanhamento de canções, independente de gênero ou estilo, mas também procura abordar obras da literatura clássica de cada instrumento. Desta forma, pretende-se proporcionar um desenvolvimento técnico e um conhecimento mais abrangente sobre a tradição dos dois instrumentos, abordando-se tanto a leitura de cifras, quanto a de partituras, assim como habilidades de improvisação, arranjo e composição. Todas estas estão diretamente ligadas à atividade de professor de música. Para auxiliá-lo em sua aprendizagem e ilustrar aquilo que é proposto, os E-books possuem diversos materiais educacionais digitais como arquivos de áudio e vídeo, partituras, animações e imagens.

São poucas as diferenças entre os dois $E$-books. Nas peças e canções no site do E-book Teclado, encontramos textos e imagens chamados Protocolos que contém orientações de como tocá-las. Já o site do E-book Violão disponibiliza uma seção chamada Extras, onde podem ser colocados materiais auxiliares ao aprendizado do aluno daqueles conteúdos, como críticas de álbuns, shows, sugestões de literatura, vídeos e áudios importantes para o desenvolvimento do aluno. As maiores diferenças entre os dois E-books estão relacionadas a características próprias da didática de cada um dos instrumentos, o que seria natural se esperar.

\subsection{UNIDADES DE ESTUDOS}

Sendo utilizando conjuntamente com os E-books, a plataforma Moodle também possui papel importante no desenvolvimento da interdisciplina Seminário Integrador. Unidades de Estudos (UE) são disponibilizadas semanalmente dentro dessa plataforma. Estas UE servem como uma espécie de planejamento particular e apropriado a cada público-alvo específico, para a utilização daqueles materiais disponíveis nos E-books. As UEs dão sugestões de sequiências didáticas de trabalho com os materiais dos E-books e estão diretamente lincadas a eles. Além disso, nas UEs os alunos podem ter contato com outros materiais que lhe servirão como ampliação dos conteúdos inicialmente abordados. Num futuro próximo, como resultado de pesquisas e testes que vem sendo feitos com os alunos, sobre sua utilização do material, pretende-se que os ambientes dos E-books contenham estas UEs e que as diversas opções de seqüências didáticas estejam 
inseridas num mesmo ambiente, para que o próprio aluno possa escolher qual caminho deseja percorrer. Entretanto, é necessário que o trabalho seja desenvolvido, testado e experimentado até que se chegue a este ideal.

\section{CONCLUSÃO}

Neste trabalho foi relatada a experiência inicial de criação dos E-books Teclado e Violão Acompanhamento, métodos estes de ensino de Teclado e Violão à distância com a utilização das novas TICs, criados pelo CAEF da UFRGS, no âmbito do Programa Prolicenciatura II. Com base nos dados apresentados, conclui-se que as novas tecnologias da informação e comunicação podem ser utilizadas para o ensino de instrumento musical a distância, e que ensino de instrumento a distância não só é possível como pode acontecer com qualidade, desde que haja um bom planejamento e fundamentação sólida. Outro fator importante é que o curso seja acompanhado com disciplina e que esteja de acordo com as necessidades do público-alvo. No caso dos $E$ books aqui citados, o foco está no desenvolvimento de habilidades e competências do professor de música que utiliza o instrumento musical como acompanhador do canto, diferentemente da formação do instrumentista, focada no desenvolvimento da performance instrumental.

Diante de um panorama geral das iniciativas de cursos de nível superior em música a distância, o PROLICENMUS se destaca pela originalidade e multiculturalidade, indo ao encontro das necessidades de uma demanda que, embora caracterizada pelas diferentes culturas brasileiras, têm um aspecto em comum: são professores de música em formação.

\section{REFERÊNCIAS BIBLIOGRÁFICAS}

BRAGA, Paulo. A adaptação do curso da Oficina de Violão da Escola de Música da UFBA para a modalidade a distância. Anais do $\mathbf{X}$ encontro anual da Associação Brasileira de Educação Musical. João Pessoa, p. 12-19, 2006.

BRAGA, Paulo; TOURINHO, Cristina. "Era uma casa muito engraçada...": reflexões sobre o planejamento do ensino instrumental a distância e a criação de cursos mediados por computador . In. CONGRESSO DA ASSOCIAÇÃO NACIONAL DE PESQUISA E PÓS-GRADUAÇÃO EM MÚSICA, 16., 2006, Brasília. Anais. Brasília: ANPPOM, 2006. p. $22-26$.

BRASIL, Ministério da Educação - Secretaria de Educação Profissional e Tecnológica e Secretaria de Educação a Distância. Referenciais para Elaboração de Material Didático para EAD no Ensino Profissional e Tecnológico, 2007. Disponível em: $<$ http://www.etecbrasil.mec.gov.br/gCon/recursos/upload/file/ref_materialdidatico.pdf $>$. Acesso em: 18 fev. 2009.

Ministério da Educação - Secretaria de Educação Profissional e Tecnológica e

Secretaria de Educação a Distância. Pró-licenciatura. Disponível em: 
$<$ http://portal.mec.gov.br/seed/index.php?option=com_content\&task=view\&id=179\&Ite mid=318\#Base\%20Legal>. Acesso em: 15 jan. 2009.

Ministério da Educação - Secretaria de Educação Profissional e Tecnológica e Secretaria de Educação a Distância. Pró-licenciatura. Disponível em: $<$ http://portal.mec.gov.br/seed/index.php?option=com_content\&task=view\&id=179\&Ite mid=318\#Base\%20Legal>. Acesso em: 15 jan. 2009.

\section{E-book Teclado Acompanhamento.}

Disponível em: <http://caef.ufrgs.br/produtos/ebook2008_mec/>. Acesso em: 15 jan. 2009.

\section{E-book Violão Acompanhamento.}

Disponível em: <http://caef.ufrgs.br/produtos/ebook_violao/release_0.4/index.html>. Acesso em: 07 mar. 2009.

GOHN, Daniel. XVI Congresso da Associação Nacional de Pesquisa e Pósgraduação em Música (ANPPOM). Educação musical a distância: tecnologia, velocidade e desaceleração. Escola do Futuro/USP. Brasília - 2006. Disponível em: $<\mathrm{http}$ ///www.anppom.com.br/anais/anaiscongresso_anppom_2006/CDROM/COM/01_ Com_EdMus/sessao01/01COM_EdMus_0104-039.pdf>. Acesso em: 7 mar. 2009.

A auto-aprendizagem musical: alternativas tecnológicas. São Paulo: Annablume, 2003.

Graduate Program in Music Education. Distance Education - Auburn University. Disponível em: <http://www.auburn.edu/distance_learning/programs/ed_ctmu/>. Acesso em: 13 fev. 2009.

HENDERSON FILHO, José Rui. A formação continuada de professores de música em ambiente de ensino e aprendizagem online. Porto Alegre:Universidade Federal do Rio Grande do Sul, 2007. 250 f. Tese (Doutorado em Música - área de concentração Educação Musical) - Programa de Pós-Graduação em Música, Universidade Federal do Rio Grande do Sul, Porto Alegre, 2007.

Horizon Wimba Live Classroom e Voice Tools. Integração no Blackboard Academic Suite. Guia do docente . Disponível em: <http://www.ipg.pt/e-

learning/pdf/Horizon_Wimba_Live_Classroom_e_Voice_Tools_INTROv1.pdf >. Acesso em: 19 jan. de 2009.

NUNES, Helena de Souza. Musicalização de Professores. Livro do Professor. Porto Alegre: CAEF/UFRGS, 2005.

Musicalização de professores através da voz (MAaV). CAEF/UFRGS, 2005. Disponível em: <http://www.caef.ufgrs.br/produtos/ maav_prof > Acesso em: 09 jan. 2009.

Postgrado em Educación musical on line. Escola de Postgrado. Universitat Autònoma de Barcelona (UAB). Disponível em: 


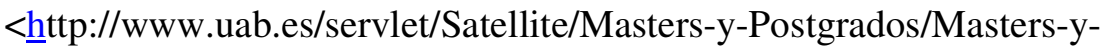

Diplomaturas/Datos-basicos-

1206597472083.html?param1=1698_2_es\&param2=2005>. Acesso em: 16 de jan. de 2009.

RANGEL, Annamaria Pífero et al. Teoria Pedagógica do Centro de Artes e Educação Física da Universidade Federal do Rio Grande do Sul: fundamentos do método empregado para a rede de formação continuada de professores. Porto Alegre: CAEF/UFRGS, 2005.

SOUZA, Cássia Virgínia Coelho de. Educação Musical a Distância para professores das séries iniciais do ensino fundamental. Em Pauta, Porto Alegre, v. 15, n. 24, p. 107 142, jan/jun. 2004.

TAROUCO, Liane; ÁVILA, Barbara. Multimídia na alfabetização digital com fluência para autoria. Revista Novas Tecnologias na Educação, Porto Alegre - RS, v.5, n.2, p.01-08, dez. 2007. Disponível em:

<http://www.cinted.ufrgs.br/renote/dez2007/artigos/1Liane.pdf>. Acesso em: 19 fev. 2009.

URTADO, Miguel. Objetos multimídia para o ensino de música online: desenvolvimento, aplicação e análise.Trabalho de Conclusão de Curso. Universidade Federal de São Carlos, São Carlos-SP, 2008. Disponível em:

$<$ http://www.canone.com.br/downloads/admin/downloads/monografia.pdf>. Acesso em: 07 mar. 2009.

VERHAALEN, Marion. Explorando a música através do teclado: guia do professor. Tradução: Denise Frederico. Porto Alegre: Editora da Universidade/UFRGS, 1989.

WALLS, Kimberly C. ; MIRANDA, Martina; SCHAFFER, Bill; GILBREATH, Jeff; \& GOOD, Rick. Program Development and Evaluation of a Distance Learning Graduate Degree Program In Music Education: Perspectives From

Students and Professors. Auburn University. S. A. 